\title{
POLÍTICA EDUCACIONAL E A RE-ESTRUTURAÇÃO DO TRABALHO DOCENTE: REFLEXÖES SOBRE O CONTEXTO LATINO-AMERICANO
}

\author{
Dalila Andrade Oliveira*
}

\begin{abstract}
RESUMO: Este artigo discute como as políticas educacionais latinoamericanas têm alterado a realidade escolar e, particularmente, a relação entre trabalhadores docentes e escola. Parte de referenciais teóricos desenvolvidos em outros contextos - Europa e América do Norte - para analisar resultados de pesquisa documental realizada sobre a política educacional em curso em alguns países latino-americanos e pesquisa empírica desenvolvida com trabalhadores docentes de escola básica pública no Brasil. Constata-se que tais políticas têm engendrado nova organização do trabalho escolar que reflete um modelo de regulação educativa, produto de novas articulaçōes entre as demandas globais e as respostas locais. Por meio da descentralização administrativa, financeira e pedagógica as escolas têm adquirido maior flexibilidade e autonomia, mas também têm respondido a uma demanda crescente de atividades e responsabilidades, o que tem contribuído para a intensificação e auto-intensificação do trabalho docente.

Palavras-chave: Trabalho docente. Política educacional. Regulação. América Latina.
\end{abstract}

\section{EDUCATIONAL POLICIES AND THE RE-STRUCTURING OF TEACHERS' WORK: REFLECTIONS ON THE LATIN-AMERICAN CONTEXT}

ABSTRACT: This paper discusses how the Latin-American educational policies have altered school reality and, more particularly, the relationship between teachers and school. Based on references developed in other contexts - Europe and North America -, it analyses the results of documental research on the educational policies cur-

Pós-doutora em Educação e professora da Faculdade de Educação e do Programa de PósGraduação em Educação da Universidade Federal de Minas Gerais (UFMG). E-mail: dalila@fae.ufmg.br

Educ. Soc., Campinas, vol. 28, n. 99, p. 355-375, maio/ago. 2007 
rently applied in some Latin-American countries and of empirical research developed with basic school teachers in Brazil. It notices that such policies have generated a new organization of school work that reflects a model of educational regulation produced by the articulation between global demands and local responses. Through their administrative, financial and pedagogic decentralization, schools have acquired more flexibility and autonomy, but have also responded to a growing demand for activities and responsibilities. This has contributed to intensify and self-intensify teachers' work.

Key words: Teacher's work. Educational policies. Regulation. Latin America.

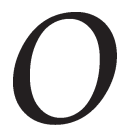

contexto educacional latino-americano reclama determinadas especificidades na análise dos processos de reforma e reestruturação do trabalho docente, em relação ao que se assiste no continente europeu e na América do Norte nos anos de 1990. Tais especificidades se explicam pela contradição imanente às reformas aqui implantadas, ou seja, a persecução dos princípios de equidade social esbarra nos limites de uma realidade em que o mínimo não está assegurado para a maioria da população. $\mathrm{O}$ objetivo deste texto é lançar elementos para a reflexão de como os critérios adotados pelas políticas educacionais atuais no contexto latino-americano alteram a realidade escolar e, particularmente, a relação entre trabalhadores docentes e escola, o que tem colocado em risco a capacidade destas políticas de promoverem justiça social.

Os esforços de análise contidos neste texto são relativos a resultados de pesquisa documental realizada sobre a política educacional em alguns países latino-americanos (Argentina, Brasil e Chile) ${ }^{1}$ e pesquisa empírica desenvolvida com trabalhadores docentes de escola básica pública, em que se procurou observar os efeitos das reformas educacionais sobre o trabalho escolar ${ }^{2}$ (Oliveira, 2006).

Encontramo-nos diante de uma nova organização do trabalho escolar, resultado de reformas implantadas nos últimos anos, que nos indica que a escola não é mais a mesma do contexto em que foram organizados os sistemas escolares e, consequentemente, os sindicatos. Essa nova organização escolar reflete um modelo de regulação educativa, produto de novas articulaçóes entre as demandas globais e as respostas locais. Por meio da descentralização administrativa, financeira e pedagógica, 
as escolas têm adquirido maior flexibilidade e autonomia, mas também têm respondido a uma demanda crescente de atividades e responsabilidades. A autonomia da escola resulta também em maior autonomia dos envolvidos, em especial os professores. Esse modelo regulatório tem levado à intensificação e auto-intensificação do trabalho (Hargreaves, 1998), por meio da mobilização da subjetividade dos trabalhadores (Ball, 2002), que se sentem auto-responsabilizados por suas tarefas, seu desempenho, sua formação e atualização e até mesmo pelo sucesso ou fracasso do aluno ou da escola.

As políticas educacionais, no continente latino-americano, tiveram, nas últimas décadas, o objetivo de expansão da escolarização básica. Essas políticas revelaram um movimento contraditório, uma vez que democratizaram o acesso à escola ao custo da massificação do ensino. Algumas pesquisas realizadas na Região têm demonstrado que a incorporação de novos setores sociais à educação, em um contexto de restrição de recursos, trouxe profundas conseqüências no desenvolvimento posterior dos sistemas educativos, com efeitos diretos sobre as condições de trabalho e as remuneraçôes dos professores (Birgin, 2000; Tiramonti, 2001; Oliveira, 2004, 2006). Tais políticas vieram por meio de reformas em um contexto de reestruturação do capitalismo que, na realidade latino-americana, resultaram em reformas ao nível do Estado, alterando substantivamente as relaçooes entre Estado e sociedade (Salama \& Valier, 1997).

Essas reformas trazem uma nova regulação educativa caracterizada pela centralidade atribuída à administração escolar - a escola como núcleo do planejamento e da gestão; o financiamento per capita, a regularidade e ampliação dos exames nacionais de avaliação, a avaliação institucional e a participação da comunidade na gestão escolar (Medina \& Kelly, 2001; Birgin, 2000; Feldfeber \& Oliveira, 2006). A configuração dos sistemas educativos é alterada nos seus aspectos físicos e organizacionais, sob critérios de produtividade e excelência, expressando uma regulação que, embora dirigida à instituição pública e estatal, encontra-se fortemente ancorada no mercado (Barroso, 2003, 2006; Lessard, 2004; Maroy, 2006). A noção de justiça social vê-se mesclada e confundida com os princípios de eficácia que, a partir deste momento, passam a orientar as políticas públicas educacionais.

Este artigo pretende discutir algumas tendências presentes nessa regulação educativa no subcontinente latino-americano, observadas em 
Política educacional e a re-estruturação do trabalho docente...

pesquisas realizadas (Oliveira, 2005, 2006) e utilizando referenciais de análises produzidas em outros contextos - Europa e América do Norte (Barroso, 2006; Van Zanten, 2006; Lessard, 2004, 2006). A utilização de tais referenciais leva em consideração as observações de Derouet (2006), de que a transferência de conhecimento de um mundo para outro deve implicar em que os conceitos elaborados em um meio, e por isso mesmo em função das relações que ali se estabelecem, sejam parcialmente desconstruídos e reproblematizados para fazer sentido dentro dessa nova realidade.

\section{A educação no contexto latino-americano}

Discutir as políticas educacionais latino-americanas nos coloca alguns desafios difíceis de enfrentar. A diversidade regional que a América Latina comporta, refletida em diferentes culturas, línguas e processos políticos nacionais, impede que pensemos esta realidade no singular e coloca limites a generalizações. A identidade latino-americana encontra seu primeiro obstáculo na língua. Apesar da predominância do espanhol como idioma oficial na maioria dos países da América do Sul e Central, em termos territoriais, grande parte do subcontinente sul-americano tem como língua oficial o português. A integração latino-americana esbarra-se neste primeiro entrave, as dificuldades lingüísticas muitas vezes nos impedem de estabelecermos elos entre culturas e realidades socioeconômicas muito próximas. Parto aqui de uma referência que, embora em crise, permanece sendo organizadora dos meios econômicos, culturais e políticos que sustentam a humanidade. Refiro-me a noção de Estado-nação da forma como a concebemos, resultado da modernidade e, portanto, uma criação até certo ponto bastante artificial e autoritária (Bhabha, 1998). Isso porque, como observa Ianni (1988), a integração latino-americana é historicamente atravessada pela questão nacional, onde as guerras e revoluções de independência estão na origem da nação, estabelecendo alguns dos seus traços principais. Para este autor, os desencontros entre a sociedade e o Estado são desafios práticos e teóricos permanentes nos países da América Latina, no continente e nas ilhas. Por isso, identificava um círculo vicioso que provoca um movimento circular cumulativo, explicado por uma história de miséria, violência e autoritarismo. Para Ianni, a história da América Latina estaria atravessada pelo precário, provisório, inacabado, mestiço, 
exótico, deslocado, fora do lugar, folclórico. "Nações sem povo, nem cidadãos; apenas indivíduos e população (...). Por isso, dizem, o Estado é forte, a democracia episódica, a ditadura recorrente. São as elites deliberantes - militares, civis, oligárquicas, empresariais, tecnocráticas que sabem e podem" (1988, p. 2).

$\mathrm{Na}$ opinião do autor, os desencontros entre sociedade civil e Estado poderiam ser explicados pelas sucessivas crises, golpes de Estado, ditaduras e interrupções de experiências democráticas que assinalam o periódico divórcio entre as tendências predominantes na sociedade civil e as do Estado, já que as revoluções burguesas verificadas nos países latino-americanos não resolveram satisfatoriamente aspectos básicos da questão nacional. Em quase todos os países não se formou o povo como coletividade de cidadãos. O operário, camponês, empregado e outras categorias, muitas vezes como índio, negro ou branco, não ingressaram de forma ampla nos espaços da cidadania.

Esta questão está na base do debate educativo na América Latina. As diversidades e desigualdades sociais, raciais, regionais e culturais, expressas em termos políticos e econômicos, mostram que a fisionomia da nação pouco ou nada reflete da cara do povo. E os sistemas escolares, como produto desta organização nacional, não ficaram imunes a esse processo. Organizados a partir de modelos externos à experiência latinoamericana, tais sistemas refletem em si a estrutura desigual e ambivalente dessa sociedade, o que resulta em conflitos de várias ordens. Segundo Tiramonti (2001), o desenvolvimento das desigualdades não teve as mesmas características em todos os países. Enquanto em alguns a ampliação da oferta pública de educação gerou processos de segmentação dentro dos sistemas públicos, fazendo surgir um espaço de comunicação entre os diferentes setores incorporados à educação (caso dos países que desenvolveram cedo a modernidade e expandiram seus sistemas educativos), em outros, a incorporação de setores emergentes à oferta educativa pública levou a uma retirada das elites deste circuito (Colômbia e Brasil), negando, assim, desde o princípio, espaços comuns de socialização àqueles que passavam a ter acesso à escola.

Os movimentos recentes que promoveram a eleição de novos governos latino-americanos com o apoio popular parecem tentar negar essa tradição histórica apontada por Ianni. Ancorando-se na busca e reconhecimento de uma identidade cultural como povos autóctones, 
somada à condição econômica, líderes indígenas como Evo Morales, na Bolívia, ou operários como Luiz Inácio Lula da Silva, no caso do Brasil, são eleitos. A busca de identidade cultural, aliada à condição de pobre, trabalhador, assentada no reconhecimento à igualdade, parece ter sido o grande mote das campanhas presidenciais mais recentes. Nesses casos, a luta contra a exploração é tomada como uma questão nacional, mas a nação é compreendida em um sentido cultural e até racial, em que a territorialidade, de maneira controversa, torna-se elemento secundário. Assim, esses movimentos podem estar expressando mais a luta pelo reconhecimento da nação cada vez mais autóctone, contrapondo-se aos governos elitistas e autoritários que, por muitas décadas, estiveram vinculados aos interesses internacionais.

Ao lado desses governos, muitas vezes envolvidos em suas campanhas ou mesmo participando ativamente da administração pública, estão os movimentos sociais que assumem também novas configurações. Os movimentos insurgentes hoje no campo educativo, expressão de demandas sociais amplas, buscam conquistar direitos de inclusão e participação na esfera cidadã. São índios, negros, mulheres, camponeses, mas, sobretudo, pobres, grupos que se identificam e reclamam condição social distinta, em que a educação é meio indispensável. Esses movimentos têm traduzido uma difícil equação, em que políticas de ações afirmativas são reclamadas em um contexto onde os direitos mínimos universais não estão assegurados. É neste contexto que justiça social e eficácia econômica se misturam, afetando diretamente a organização e gestão escolares.

A escola, os trabalhadores docentes e o contexto educacional latinoamericano

A crença na escola como meio de inserção social qualificada resiste em meio às crises de desemprego e vulnerabilidade das economias nacionais, que põem em risco cada vez mais a promessa de futuro para as gerações mais jovens. A escola formal ainda é objeto de luta - acesso e qualidade - nos movimentos organizados na América Latina, enquanto o direito à educação for algo a ser conquistado para a grande maioria da população latino-americana. São essas lutas que, em muitos casos, levam a educação regular a comunidades longínquas, pobres ou mesmo a periferias dos grandes centros urbanos. As políticas educacionais mais 
recentes têm refletido a busca de resposta a esses movimentos, ao mesmo tempo em que trazem uma nova conformação da coisa pública, alterando o sentido do que seja atendimento e cobertura.

Essa tendência que assume certas particularidades no contexto latino-americano é observada em outras realidades nacionais. Derouet (2006) demonstra como esse processo se desenvolve na França. O século XX assistiu ao desenvolvimento dos sistemas escolares orientados pelos princípios de igualdade e universalidade. O ideal de escola republicana desenvolveu-se em contraposição à formação de excelência das elites. $\mathrm{O}$ ideal de igualdade de oportunidades e o interesse geral foram os princípios orientadores dos planos nacionais de educação que desenvolveram os sistemas escolares, sobretudo na segunda metade do século passado. Os reclamos de justiça social apontavam para a necessária universalização da educação, princípio norteador e definidor de uma concepção de política social. A partir das críticas surgidas nos anos de 1960, que colocaram em xeque os valores de igualdade de oportunidades e os critérios de justiça social, constata-se o enfraquecimento da noção de compromisso nacional. Segundo o autor, toda redução desta complexidade será percebida como uma ameaça de totalitarismo. O relativismo resultado dessas críticas é introduzido no plano da organização, por meio da concorrência regulada entre os estabelecimentos como fator de eficácia e igualdade. É quando começa, com Lionel Jospin, as mudanças no plano legal, fundadas no sentido de compromisso local: "todos diferentes, porém ligados por uma intenção de interesse geral".

Mesmo nos países latino-americanos, em que não chegamos a conquistar o Estado de Bem-Estar Social, assistimos ao desenvolvimento e organização dos sistemas escolares dirigidos à universalidade, ainda que não a tenhamos logrado na sua maioria. A modernização da sociedade latino-americana, orientada para o progresso econômico, teve nos sistemas escolares um de seus grandes baluartes. Ao mesmo tempo em que a escola formal ia se organizando e tornando-se uma realidade a favor da melhoria das condiçôes de vida dessas populações, traduzia-se também em condiçóes objetivas para o desenvolvimento econômico desses países. A ideologia do nacional-desenvolvimentismo pressupunha a escolarização da população como um processo civilizatório. A educação pública como política social universal aparecia como concessão de direitos sociais outorgados pelo Estado, ainda que, em muitos casos, precedidas de grandes 
Política educacional e a re-estruturação do trabalho docente...

mobilizações dos trabalhadores. Tal período representou grande prosperidade econômica, trazendo maior urbanismo, escolarização, previdência social e saúde pública, mesmo não sendo tais políticas satisfatoriamente realizadas para a maioria da população. Esses anos representaram, em todo o mundo, o ápice de um modelo de regulação social em que os sindicatos foram importantes interlocutores (Castel, 1999).

Referindo-se a esse momento, Tiramonti (2001) considera que o setor docente e seus representantes sindicais estiveram duplamente ligados à organização inclusiva da sociedade e à sua instância de dominação na América Latina. Isso porque tiveram sua existência assegurada pela expansão das classes médias, que demandaram um Estado docente e a ampliação dos serviços educativos. Assim, os sindicatos foram incorporados à estrutura de dominação, participando ativamente dos processos de normalização do setor e de regulamentação da atividade de seus membros. Para essa autora, no marco do Estado social que se instalou na América Latina a partir dos anos de 1940 e da posterior hegemonia da teoria do capital humano, que acompanhou o crescimento econômico dos anos de 1960, incentivando o desenvolvimento dos sistemas educativos nacionais, assistiu-se ao crescimento do número de matrículas e à conseqüente incorporação de novos setores aos sistemas educativos. Em muitos países latino-americanos, os sindicatos participaram ativamente na elaboração das normas e regulamentos do setor em diferentes momentos, conforme o desenvolvimento dos sistemas educativos -, contribuindo na definição dos estatutos docentes. Ainda que os sindicatos tenham se incorporado à regulação estatal nesse período, tal articulação adquiriu formas distintas nos diferentes países, em função da estrutura institucional de poder, das características das elites de governo e da cultura política dominante.

\section{Os sindicatos e a organização dos trabalhadores de educação}

As organizações sindicais vêm sofrendo enfraquecimento contínuo nas últimas duas décadas, com práticas consideradas incapazes de responder às exigências trazidas pelas mudanças mais recentes no trabalho. No caso latino-americano, mais especificamente os países que compõem o MERCOSUL, a liberdade de organização sindical sofre direta ou indiretamente limitações que resultam em organizações fragmentadas e fracas, refletindo nas estruturas supranacionais, aumentando as 
dificuldades de integração efetiva dos trabalhadores da Região. O enfraquecimento dos sindicatos é atribuído à diminuição dos sindicalizados e à fraca participação dos trabalhadores. Dentre vários fatores contributivos para esse processo, destacam-se: a redução do número de empregos, principalmente nos grandes centros industriais, o avanço da tecnologia; a desregulamentação das relaçôes de trabalho e o recurso à informalidade. Nesse contexto, as críticas - muitas delas conservadoras - ao papel do sindicato vêm contribuindo para o seu enfraquecimento. A denúncia do alto grau de corporativismo dessas instituiçōes, seu caráter estatizante, conservador, retrógrado, vem dos empresários e de setores neoliberais que defendem a autonomia e liberdade sindical, atacando o direito do trabalho como legislação protetiva e assistencialista.

A crise dos sindicatos em todo o mundo, coerente à crise das instituiçôes modernas (Touraine, 1994), põe em evidência o papel ambíguo que tais entidades tiveram ao longo do século Xx (Bernardo, 1987). Essas mesmas entidades, ao mesmo tempo em que legitimaram o processo de desenvolvimento capitalista, fundado na exploração da força de trabalho, também representaram importante espaço de luta democrática e de resistência às formas de exploração. Essa crise geral do sindicalismo adquire contornos próprios no caso dos docentes.

Segundo Tiramonti (2001), o surgimento de sindicatos de professores nos diversos países da América Latina está relacionado ao desenvolvimento dos sistemas educativos com os modelos de acumulação adotados, as necessidades do Estado de ampliar sua base social e os regimes políticos vigentes. Assim, os países que se modernizaram cedo, que se desenvolveram com base em modelo que abrangia os diferentes setores sociais e que, desde o princípio do século, apresentaram um crescimento significativo de seus sistemas educacionais, registram também cedo uma conformação de movimentos de professores. Tais movimentos transformaram-se em sindicatos na metade do século, como parte do processo de reestruturação da ordem social que produziu o modo particular como a América Latina processou a crise do capitalismo dos anos de 1930 e implementou as propostas keynesianas do pósguerra. São os casos da Argentina, do Chile e do México.

No caso brasileiro, a estrutura sindical implantada nos anos de 1940 era de caráter corporativo e autoritário, herdada da "Carta del Lavoro", de Mussolini, e atrelava os sindicatos ao Estado por meio da 
Política educacional e a re-estruturação do trabalho docente...

concessão do direito de outorga, da unicidade e do imposto, fonte de financiamento e sustentação dos sindicatos até os anos de 1980. Os funcionários públicos estavam impedidos de organizarem sindicatos, o que incluía a grande maioria dos docentes. No movimento de abertura política que o Brasil viveu em fins de 1970 e início de 1980, os trabalhadores da educação pública, em vários estados brasileiros, participaram ativamente nas greves, inclusive de fome, reivindicando organização sindical livre e autônoma. A luta, naquele momento, foi pelo reconhecimento de uma categoria mais ampla de trabalhadores na educação pública, que contemplasse não só os professores, mas os demais funcionários das escolas e do sistema. Esses movimentos protagonizaram o pleito por projetos de educação alternativos. $\mathrm{Na}$ resistência ao regime autoritário, movimentos de base se estruturaram em torno da defesa da educação popular. Muitas dessas propostas tinham inspiração socialista ou libertária. A luta por nova sociedade trazia a luta por novo projeto educativo, tendo o trabalho como princípio de formação humana. Essas lutas de caráter eminentemente humanista vincularam a defesa da universalização da educação à melhoria das condiçôes de trabalho docente. Estava na base dessa discussão o reconhecimento da necessidade de organização classista da sociedade em defesa dos direitos dos trabalhadores em geral.

Os sindicatos de docentes, no Brasil, se organizaram nesse período tendo como princípios: defender os direitos e interesses da categoria profissional e de cada trabalhador em educação, inclusive aposentados; desenvolver a unidade de toda a categoria dos trabalhadores em educação, bem como desta com os demais trabalhadores; participar, ao lado destes, no combate às formas de exploração e opressão; incidindo essas defesas em uma nova política educacional congruente aos interesses da maioria trabalhadora. Esses sindicatos se instituíram como representantes dessa categoria, garantindo sua independência e assegurando sua autonomia frente às entidades patronais, organizações religiosas, partidos políticos e em relação ao Estado.

Na década de 1990, os trabalhadores da educação, na América Latina, viram-se submetidos a políticas de arrocho salarial, o que acarretou grandes perdas econômicas. Os mecanismos que corroboraram para a deterioração das condiçôes de trabalho e remuneração desses trabalhadores foram medidas de flexibilidade da legislação do Direito do Trabalho, permitindo maior diversificação salarial. O aumento do número de professores contratados temporariamente, em condições precárias no 
setor público, é o exemplo mais significativo (Tenti Fanfani, 2005). Em alguns casos, como o do Brasil, a política salarial do setor público apresenta grande diversidade, os vencimentos dos docentes se diferenciam em função da carreira, do contrato de trabalho - efetivo ou temporário -, do cargo, do regime de trabalho, do nível e da classe, do tempo de serviço, das gratificações incorporadas, da titulação. Outro elemento que contribui nessa diversificação é a diferença econômica regional que o país comporta, apresentando enormes discrepâncias entre os trabalhadores de diferentes redes públicas municipais e estaduais com mesma formação e titulação, trabalhando em condições idênticas, sem, contudo, terem a isonomia salarial garantida.

As associações e sindicatos de docentes, atualmente na América Latina, enfrentam a difícil tarefa de organizar e responder às diversas formas de expressão da indignação, da revolta e resistência dos trabalhadores de educação para com o processo de precarização de suas condições de trabalho, trazidas pela massificação do ensino e pelos novos dispositivos regulatórios (Oliveira \& Melo, 2004). Os sindicatos vivem esses desafios ao mesmo tempo em que sofrem o desgaste que o conjunto dos sindicatos tem vivido como resultado dos processos de reestruturação produtiva, com a diminuição do trabalho formal e regulamentado e o enfraquecimento na cena política. É como se os sindicatos tivessem, na atualidade, o duplo desafio de se defenderem como instituição e aos trabalhadores como categoria. Porém, em determinadas circunstâncias, essa luta se torna paradoxal, devendo o sindicato atuar na defesa de interesses constitutivos do campo de relações entre sociedade civil e Estado pelo direito à educação, como um princípio de justiça social - por exemplo, a defesa da escola de tempo integral - e, em outras circunstâncias, exigir a diminuição da jornada de trabalho dos docentes, adotando estratégias de greves e paralisaçóes. O conflito para os sindicatos representa um mecanismo que mede as relaçóes de força, habilita a negociação e atualiza permanentemente o compromisso entre as partes envolvidas. Cada negociação permite ao sindicato renovar suas credenciais de mediador e negociador das demandas da base e propicia aos governos a construção de consensos políticos. A confrontação reivindicatória por melhores salários e condições de trabalho foi, e ainda tem sido, a linha de continuidade na ação dos sindicatos de educação na América Latina.

Tiramonti (2001) observa que, no processo de reconstituição de um sentido que estruture sua ação, os sindicatos apelam para diferentes 
Política educacional e a re-estruturação do trabalho docente...

discursos para fundamentar suas propostas e práticas. Neste amplo espectro retórico, há interpelações classistas, impugnações gerais ao modelo de desenvolvimento, demanda pela recuperação da função docente do Estado, reclamos pela situação dos excluídos, exigência de um reconhecimento profissional e também a recuperação das propostas que reivindicam a lógica do mercado para organizar o sistema educativo. Entre ambos os extremos, encontramos discursos híbridos que se constroem a partir de uma permanente transação com as situações de fato que os sindicatos têm de enfrentar. Por exemplo, tentar recuperar formas de mobilização que não estejam exclusivamente atreladas ao incentivo salarial, mas também à estima profissional e ao valor intelectual do trabalho.

Os trabalhadores da educação e a luta pela autonomia no quadro de nova regulação educativa na América latina

As reformas educacionais que na última década foram implantadas na maioria dos países latino-americanos foram marcadas pela descentralização administrativa, financeira e pedagógica, atribuindo maior autonomia aos estabelecimentos escolares. Tal descentralização veio acompanhada de processos de padronização de procedimentos administrativos e pedagógicos, como meios de garantir o rebaixamento dos custos da expansão do atendimento e redefinir gastos, sem, contudo, abrir mão do controle central das políticas. Por meio dos currículos centralizados, o livro e material didático, vídeos, programas de computadores, a regularidade dos exames nacionais de avaliação e a prescrição normativa sobre o trabalho pedagógico, observa-se relativa padronização nos processos escolares. No Brasil, com os artigos 12, 13 e 14 da Lei de Diretrizes e Bases (LDB) n. 9.394/96, observa-se um forte acento no trabalho coletivo, o que passa a exigir que os professores participem da elaboração do projeto pedagógico e adotem maior flexibilidade e transversalidade em suas práticas por meio dos currículos e das avaliações. As críticas à organização seriada, como um dos elementos causadores da crise educacional, ou do caráter excludente da escola, fizeram com que algumas redes públicas adotassem a organização escolar por ciclos. Tais medidas foram amplamente reforçadas pelas alteraçóes ao nível da legislação educacional nacional, por meio da já mencionada LDB n. 9394/96, pelos Parâmetros Curriculares Nacionais, pelo Sistema Nacional de Avaliação da Educação Básica (sAEB), entre outras. 
No que se refere ao domínio administrativo, amplia-se substancialmente as responsabilidades e atividades no nível local, por meio da abertura para a contratação de serviços e compra de material. No âmbito da gestão escolar, observa-se a ampliação do espaço de manobra para conduzir as políticas internas e flexibilidade administrativa que dotam a escola de maior autonomia institucional. A descentralização administrativa que se observa tem representado a transferência de obrigações dos órgãos centrais às escolas, sobretudo por meio de programas especiais. A descentralização administrativa e financeira permite à escola maior flexibilidade na gestão e captação de recursos externos. Essa é uma importante dimensão no quadro de reorganização das políticas sociais, pois essas passam a depender cada vez mais da capacidade de captação de recursos no meio local. Essas reformas têm resultado em reestruturação do trabalho pedagógico, proveniente da combinação de diferentes fatores que se fazem presentes na gestão e organização do trabalho escolar, tendo como corolário maior responsabilização dos professores e maior envolvimento da comunidade.

A descentralização tal como é adotada, a partir dos processos de reforma mais recentes do Estado, tem por objetivo diminuir a burocracia escolar. Na prática, na busca de maior eficácia, amplia-se o poder de decisão da escola sobre um conjunto de ações, mesmo sabendo-se que as formulações não estão descentralizadas a esse nível. Como acentua Lessard (2006), essa autonomia não é mais uma resposta contra a organização, mas uma nova prescrição dela. $\mathrm{O}$ quadro que regulamenta essas mudanças também traz maiores poderes aos alunos e pais de alunos, sejam como parceiros da gestão, sejam como sujeitos políticos do processo. No caso do Brasil, o Estatuto da Criança e do Adolescente (ECA) e os conselhos que se multiplicaram a partir da LDB n. 9.394/96 são bons exemplos. O paradoxo desse modelo regulatório é que, ao mesmo tempo em que cresce a autonomia dos sujeitos, também cresce o controle sobre eles. Esse modelo de autonomia está centrado em maior responsabilização dos envolvidos, que têm de responder pelo que fazem, como fazem e para que fazem. Sendo assim, aumenta a responsabilidade dos trabalhadores docentes sobre o êxito dos alunos, ampliando os raios de ação e competência desses profissionais. O desempenho dos alunos passa a ser algo exaustivamente mensurado, avaliado sistematicamente por instrumentos que não são elaborados no contexto escolar. Da mesma maneira, são muitas as demandas que chegam a esses trabalhadores como provas e exigências 
Política educacional e a re-estruturação do trabalho docente...

de sua competência em conseguir responder às prescriçōes de ordem orçamentária, jurídica, pedagógica e política.

Os trabalhadores docentes se vêem então forçados a dominarem práticas e saberes que antes não eram exigidos deles para o exercício de suas funçōes e, muitas vezes, recebem tais exigências como resultados do avanço da autonomia e da democratização da escola e de seu trabalho. Assim, o trabalho docente passa a contemplar as atividades em sala de aula, as reuniôes pedagógicas, a participação na gestão da escola, o planejamento pedagógico, entre outras. Tais exigências são coerentes com uma nova regulação educativa que, em certa medida, com as reformas educacionais mais recentes, toma lugar em muitos países no mundo (Dutercq \& Lang, 2002; Cattonar \& Maroy, 2001; Barroso, 2004; Lessard, 2004). Como observa Lessard (2006, p. 145), ancorado em revisão de alguns autores sobre o tema da regulaçáo, "não se trata de reivindicar uma autonomia contra a organização, suas regras formais e sua hierarquia burocrática, mas de assumir a autonomia, a cooperação e a prestação de contas que a organização impóe aos seus atores. Estaríamos agora na era da autonomia prescrita e da iniciativa obrigada ou forçada”. Então, não se trata mais de reivindicar uma autonomia contra a organização, mas de assumir a autonomia, a cooperação e a prestação de contas que a organização impõe.

A autonomia reclamada pelos trabalhadores docentes organizados em suas associaçóes e sindicatos mesclava elementos de autonomia profissional e institucional. A autonomia buscada pelos professores dizia respeito, sobretudo, a sua liberdade para organizar seu trabalho, administrar seu tempo, ou seja, ter maior controle sobre o processo de trabalho. Para o alcance dessa autonomia era necessário que a instituição escolar também fosse mais autônoma, isto é, que tivesse maior liberdade de auto-organização. Assim, a autonomia corporativa dependia necessariamente da autonomia institucional da escola, ainda que uma autonomia relativa, sabendo que a escola está inserida em um sistema e que os docentes referem-se a uma autonomia que lhes preserve a condiçāao de funcionários públicos, estatutários, com direitos e garantias das quais não pretenderam jamais abrir mão. A contrapartida da autonomia dos trabalhadores docentes é a autonomia da escola, mas esta implica também aumentar o poder dos outros segmentos que participam da comunidade escolar. Assim, à medida que os trabalhadores docentes adquirem maior autonomia, o mesmo se passa com os alunos e pais de alunos e com a comunidade no seu entorno. A autonomia da escola, adquirida por meio 
dos processos de descentralização, acima referenciados, traz maiores custos para os trabalhadores docentes. Ao mesmo tempo em que ganham maior autonomia, liberdade de definir certas regras do seu dia-a-dia, como o calendário, a escolha de um tema transversal que deverá ser trabalhado por toda a escola, definir projetos, discutir coletivamente saídas e estratégias para desafios encontrados localmente, buscar recursos para além dos ordinários, os trabalhadores docentes se tornam mais presos às suas atividades e compromissos. A responsabilização sobre os destinos da escola, dos alunos, dos projetos passa a ser cada vez maior. É como se os trabalhadores docentes tivessem que pagar o preço por esta autonomia conquistada, já que é resultante de suas lutas.

As velhas estruturas hierárquicas e estáveis vão sendo substituídas por outras mais flexíveis, porém muito mais instáveis. A segurança obtida por meio de estruturas que são tradicionalmente conhecidas, em que os sujeitos envolvidos conheçam bem as regras, ainda que não possam formulá-las ou alterá-las em seu favor, vai se perdendo. As hierarquias burocráticas, o autoritarismo, a impessoalidade, a verticalização das estruturas cedem a formas mais horizontais e coletivas, porém mais instáveis e menos conhecidas, mais vulneráveis. Estamos diante de uma outra regulação, em que o estatuto profissional burocrático vai perdendo sua força orientadora frente à emergência de uma outra orientação, fundada no contrato permanente, exigente de maior diálogo e, por isso mesmo, muito mais instável e sujeita ao risco. A transição entre esses modelos de regulação implica um processo de hibridismo, em que novas práticas vão sendo assumidas ainda sob as lógicas burocráticas (Barroso, 2006).

Segundo Giddens (2002), quanto mais a tradição perde seu domínio e quanto mais a vida diária é reconstituída em termos do jogo dialético entre o local e o global, tanto mais os indivíduos são forçados a escolher um estilo de vida a partir de uma diversidade de opçóes. Isso ocorre como resultado da "abertura" da vida social de hoje, com a pluralização dos contextos de ação e a diversidade de "autoridades". O autor observa que a escolha de estilo de vida é cada vez mais importante na constituição da autoidentidade e da atividade diária. O planejamento de vida reflexivamente organizado, que normalmente pressupóe a consideração de riscos filtrados pelo contato com o conhecimento especializado, torna-se uma característica central da estruturação da auto-identidade. Para Giddens (2002), o mundo da alta modernidade estende-se para além dos domínios das atividades individuais e dos compromissos pessoais, estando repleto de riscos e 
Política educacional e a re-estruturação do trabalho docente...

perigos, "para os quais o termo 'crise' - não como mera interrupção, mas como um estado de coisas mais ou menos permanente - é particularmente adequado" (p. 19). As transformações na auto-identidade e a globalização são os dois pólos da dialética do local e do global nas condições da alta modernidade. A modernidade rompe o referencial protetor da pequena comunidade e da tradição, substituindo-as por organizações muito maiores e impessoais. $\mathrm{O}$ indivíduo se sente privado e só, num mundo em que lhe faltam o apoio psicológico e o sentido de segurança oferecidos em ambientes mais tradicionais. As análises de Giddens nos ajudam a pensar a complexidade que a realidade atual enseja. Há muito a se conhecer sobre esses novos processos de organização social em que a escola é parte importante. $\mathrm{Na}$ suas múltiplas e complexas relações, a escola espelha o risco e a insegurança que marcam os dias atuais.

\section{Considerações finais}

A atual onda de novos governos populares, na América Latina, poderia estar sinalizando para novos tempos em que é observada uma ruptura com o processo descontínuo assinalado por Ianni (1988). Experimentamos uma onda de governos progressistas neste subcontinente que tiveram início na década passada, representados por governos como o da Venezuela, Brasil, Argentina, Uruguai, Bolívia e, mais recentemente, Nicarágua, que, a despeito do apoio recebido por segmentos organizados da classe trabalhadora, refletido nas propostas que antecederam as eleições, tem se definido no conjunto de suas ações por manter a mesma lógica estrutural das reformas educativas iniciadas por seus antecessores, com algumas poucas exceções. Nesse sentido, não é possível obter um retrato aproximado do contexto de reformas levadas a cabo na última década, na América Latina, sem incluir as que ocorrem em governos de orientação "democrático-popular". Mesmo em realidades nacionais marcadas pela mudança radical nas orientações de governo, observa-se um forte acento às políticas de caráter temporário, compensatórias, destinadas, portanto, aos grupos mais vulneráveis socialmente, em detrimento daquelas regulares, orientadas por princípios universais e de caráter estável (Salama \& Valier, 1997). Programas como o Bolsa-Escola (Brasil, México, Argentina) e as políticas de cotas nas universidades públicas (Brasil) são alguns desses exemplos. Somadas a isso, a manutenção dos sistemas de avaliação externa nos mesmos padrões dos governos anteriores (Chile, Brasil e Argentina) e, ainda, a instituição do 
financiamento per capita, orientado por uma lógica mercantil (Chile, Brasil, Argentina, entre outros), herança da monetarização das relações sociais, introduzida no contexto escolar pelas reformas neoliberais.

Tais governos foram eleitos por base social distinta da que sustentou governos autoritários anteriores, portanto, estão imbuídos de expectativas dos setores populares que aspiram novas políticas em novos governos. Nesse sentido, novas políticas deveriam ensejar novos projetos educativos. Os movimentos sociais organizados, na América Latina, têm revelado novas propostas educativas que podem ser apropriadas e disseminadas por outras partes da Região, a exemplo, aquelas formuladas na luta pela terra do Movimento dos Trabalhadores Rurais Sem-Terra (MST), no Brasil, os Barrios de Piés, na Argentina, as Caravanas Pedagógicas da Colômbia, entre outras. Mas, se esses movimentos sociais encontram alguma semelhança em suas formas de atuação e seus objetivos políticos, sua integração institucional para a ampla defesa de um novo projeto educativo para a América Latina não tem sido observada. A força e institucionalidade dos governos e dos organismos internacionais, na América Latina, acabam por definir os limites de atuação e as formas de organização da educação na Região.

No contexto latino-americano, em que novos governos emergem com a promessa muitas vezes de novos projetos educativos, a distância entre os movimentos instituídos nos sindicatos e partidos políticos das manifestações cotidianas autônomas - nas diferentes formas que estas assumem - pode pôr em risco a possibilidade, talvez inédita, de uma integração regional que seja a expressão popular de suas nações. A defasagem entre os projetos educativos construídos sob a referência dos trabalhadores na luta, na experiência, é negligenciada ante aqueles pensados, normalmente por peritos dos organismos internacionais, como a salvaguarda para a América Latina e África, condenadas à pobreza. É a revalorização da técnica em detrimento da política, mas sob o eufemismo da participação. A dependência político-econômica desses governos com tais organismos e o lugar secundário que ocupa a educação nesse cenário talvez expliquem a pouca força que os movimentos instituintes têm tido mesmo nos governos que saíram de suas bases. Como nas palavras de Ianni (1988, p. 12):

Há conjunturas críticas nas quais o Estado e a sociedade civil dissociam-se bastante, estranham-se amplamente. (...) o povo resiste, subsiste. Mas dá a 
impressão de que vaga perdido na solidão dos pampas, coxilhas, planaltos, costas, serras, montanhas, vales, matas, campos e construções. Muitos são obrigados a confinar-se dentro de si. Parecem sonâmbulos, zumbis extraviados de um país inexistente.

Constata-se que, no contexto latino-americano, vive-se um conturbado processo de reformas no nível do Estado e da educação que tem penalizado uma categoria específica de trabalhadores e colocado em risco projetos de mudança. Os trabalhadores docentes estão pagando com a intensificação do trabalho o preço da sua autonomia. Isso porque as condiçôes efetivas dessas reformas têm se orientado pela contenção do gasto público, de ajustes estruturais que atuam sobre as políticas sociais, atribuindo à educação a dupla tarefa de formar a força de trabalho necessária ao desenvolvimento econômico, ao mesmo tempo em que deve contribuir na contenção e alívio à pobreza (Oliveira, 2000). No quadro de uma nova regulação social, em que o universalismo esmaecese como critério de justiça social, diversidade e desigualdade tendem a se confundir.

A difícil equação entre os direitos universais e o reconhecimento das especificidades está na base dos conflitos sociais latino-americanos e, em particular, os que se desenvolvem no setor educacional. As expectativas depositadas nos novos governos são muitas vezes contrariadas nas primeiras medidas por eles tomadas. A necessária integração latinoamericana entre os movimentos que se constituem no calor desses acontecimentos parece ser a possibilidade de ruptura com o isolamento assinalado por Ianni, para que finalmente os povos latino-americanos possam clarear a solidão dos pampas, vales e montanhas e libertar-se da condição de extraviados.

Recebido em maio de 2007 e aprovado em junho de 2007.

\section{Notas}

1. Pesquisa realizada durante estágio de pós-doutoramento na Université de Montreal (Canadá), com o apoio da CAPES, cujo objeto foram as conseqüências da nova regulação educativa na América Latina sobre o trabalho docente (Argentina, Brasil e Chile).

2. Pesquisa realizada pelo Grupo de Estudos sobre Política Educacional e Trabalho Docente (GESTRADO), sob minha coordenação, intitulada "Gestão escolar e trabalho docente", nas redes públicas de ensino de Minas Gerais. Apoio: fapemig e CNPq. 


\section{Referências bibliográficas}

BALL, S.J. Reformar escolas/reformar professores e os territórios da performatividade. Revista Portuguesa de Educação, Braga, v. 15, n. 2, 2002.

BARROSO, J. A escola pública: regulação, desregulação e privatização. Porto: Asa, 2003.

BARROSO, J. A regulação das politicas públicas de educação: espaços, dinâmicas e actores. Lisboa: Educa Autores, 2006.

BERNARDO, J. Capital, sindicatos e gestores. São Paulo: Vértice, 1987.

BHABHA, H. O local da cultura. Belo Horizonte: UfMG, 1998.

BIRGIN, A. La docencia como trabajo: la construcción de nuevas pautas de inclusión y exclusión. In: Gentili, P.; Frigotto, G. (Comp.). La ciudadanía negada: políticas de exclusión en la educación y el trabajo. Buenos Aires: CLACSO, 2000.

BRASIL. Constituição (1988). Constituição da República Federativa do Brasil. 18. ed. São Paulo: Saraiva, 1998.

BRASIL. Lei no 9.394, de 20 de dezembro de 1996. Estabelece as diretrizes e bases da educação nacional. Diário Oficial da União. Brasília, DF, 23 dez. 1996, p.27894.

CASTEL, R. As metamorfoses da questão social: uma crônica da questão social. Petrópolis: Vozes, 1999.

CATTONAR, B.; MAROY, C. Rhétorique du changement du métier d'enseignant et stratégie de transformation de l'institution scolaire. Éducation et Sociétés, Paris, v. 2, n. 6, 2001.

DEROUET, J.L. Entre la récuperation des savoirs critiques et la construction des standards du management libéral: recherche, administration et politique en France de 1975 à 2005. Revue des Sciences de l'Éducation, Quebec, v. 32, n. 1, 2006.

DUTERCQ, Y.; LANG, V. L'emergence d'un espace de régulation intermédiaire dans le système scolaire français. Éducation et Sociétés, Paris, v. 2, n. 8, 2002. 
Política educacional e a re-estruturação do trabalho docente...

FELDFEBER, M.; OlIVEIRA, D.A. (Comp.). Politicas educativas y trabajo docente: nuevas regulaciones, nuevos sujetos? Buenos Aires: Centro de Publicaciones Educativas y Material Didáctico, 2006.

GIDDENS, A. Modernidade e identidade. Rio de Janeiro: Zahar, 2002. HARGREAVES, A. Os professores em tempos de mudança: o trabalho e a cultura na idade pós-moderna. Alfragide, Pt: McGraw-Hill, 1998.

IANNI, O. A questão nacional na América Latina Estudos Avançados, São Paulo, v. 2, n. 1, p. 5-40, jan./mar. 1988.

LESSARD, C. L'obligation de resultats en éducation: de quoi s'agit-il?: le contexte québécois d'une demande sociale, une rhétorique du changement et une extension de la recherche. In: Lessard, C.; Meirieu, P. L'obligation de resultats en éducation. Montréal: Université Laval, 2004.

LESSARD, C. Regulação múltipla e autonomia profissional dos professores: comparação entre o Quebec e o Canadá. Educação em Revista, Belo Horizonte, n. 44, dez. 2006.

MAROY, C. Convergências e divergências dos modos de regulação numa perspectiva européia. In: BARROSO, J. (Org.). A regulação das políticas públicas de educação: espaços, dinâmicas e actores. Lisboa: Educa Autores, 2006.

MEDINA, S.A.; KELLY, E.P. Professionnalisme et procés de formation: l'expérience latino-américaine. Éducation et Sociétés, Paris, v. 2, n. 6, 2001.

OLIVEIRA, D.A. Educação básica: gestão do trabalho e da pobreza. Petrópolis: Vozes, 2000.

OLIVEIRA, D.A. Regulação das políticas educativas na América Latina e os trabalhadores docentes. Rio de Janeiro: UERJ, 2005. (Relatório de pesquisa de pós-doutoramento - CNPq).

OLIVEIRA, D.A. Gestão escolar e trabalho docente. Belo Horizonte: UFMG, 2006. (Relatório de Pesquisa CNPq - FAPEMIG).

OLIVEIRA, D.A.; MELO, S.D. Estudio de los conflitos en los sistemas educativos de la región: agendas, actores, evolución, manejo e 
desenlaces. Santiago: LPP; UerJ; OREALC; UnesCo, 2004. (Relatório de estudo de caso do Brasil).

SALAMA, P.; VALIER, J. Pobrezas e desigualdades no terceiro mundo. São Paulo: Nobel, 1997.

TENTI FANFANI, E. La condición docente. Buenos Aires: Siglo Veintiuno, 2005.

TIRAMONTI, G. Sindicalismo docente e reforma educativa na América Latina na década de 1990. Santiago do Chile: PREAL, 2001. (Documento, 19)

TOURAINE, A. Crítica da modernidade. Petrópolis: Vozes, 1994.

VAN ZANTEN, A. Interdependência competitiva e as lógicas de acção das escolas: uma comparação européia. In: BARroso, J. (Org.). A regulação das políticas públicas de educação: espaços, dinâmicas e actores. Lisboa: Educa Autores, 2006. 